Cat." At this workshop individuals will report to their colleagues in service committees about strengths and the weaknesses they have identified. Papers and abstracts will be collected and shared among ACLCP members and other interested groups.

\section{Continuing operations}

During the summer of 1990 all seventeen libraries submitted their databases for inclusion in the first operational edition of C. D. Cat to appear during the summer. Approved changes will be made in the database design, software, and hardware and incorporated in the production of the operational catalog. Libraries will be asked to submit databases in the spring and fall on a continuing basis.

The Grants Committee will be working to achieve some of the enhancements identified for the project. Operational funding, amounting to $\$ 495$ per member library, per year, will be added to the ACLCP operating budget. Access to the database will be provided to other libraries in the region.

The value-added, compact disk, union catalog promises to meet many of the needs for a resource sharing system in ACLCP at a modest cost. The planning process has involved many librarians at participating libraries and resulted in useful implementation plans, administrative decisions, and database design that may be useful to other consortia and systems. In the coming year, the test database will be assessed, the design modified, and the first operational database produced. At that time, we trust we can confirm the statement of one of the federal evaluators who indicated that the need is fitting, the funding suitable, and the technology appropriate.

\title{
Choosing CD-ROM products
}

\author{
By John Haar \\ Head of Collection Management \\ Virginia Commonwealth University
}

\author{
and Juleigh Clark, Sally Jacobs, \\ Frank Campbell
}

Reference Librarians

Virginia Commonwealth University

\section{A selection checklist for CD-ROM collection development.}

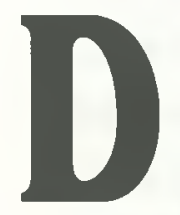

eciding which CD-ROM products are most appropriate to purchase for a library can be a much more complex process than it may appear. In fact, any purchase decision arrived at too easily may well be one that should be reconsidered. Recognizing the complexities of the task can be the first step in making a sound decision, one that weighs the impact of each CD-ROM product throughout the library. Although the most popular CD packages are reference tools, a thorough evalu- ation will reveal that their acquisition affects far more than reference service alone.

Most CD-ROM products, particularly those that require annual updates, represent a major investment. A purchase decision means obligating thousands of budget dollars for initial acquisition and assuming yearly commitments of thousands more for renewal charges, which like serial renewals can be expected to increase steadily.

This fiscal implication is all too evident, and its 
consideration is basic to any purchase decision. But other factors, some involving hidden costs, may be less noticeable in a cursory review. Among them are the provision of hardware and the availability of staff necessary for training and maintenance. Equally worthy of attention is how closely the CD product relates to academic programs the library supports and whether it provides information at an intellectual level consistent with those programs. The best decisions can be made only when all the potential outcomes of any purchase can be identified and fully investigated.

At Virginia Commonwealth University we have developed guidelines for CD-ROM selection in the form of questions that selectors must answer in a written proposal requesting funds for a CD purchase. Our intent is to encourage all selectors to ask themselves questions about a proposed purchase that involve the library-wide consequences of a CD's acquisition and use.

The questions range from the philosophical to the practical. Some require selectors to reflect upon whether the library and its patrons are best served by CD tools of a general or highly subjectspecific nature. Others necessitate a review of lease terms and long-term costs. Most are not designed to elicit "correct" answers. Rather, their intent is that selectors gather all relevant information and compare the potential advantages and disadvantages of each proposed acquisition. In this way the staff is guided toward recommending a purchase that best addresses the entire library's needs by providing information relative to local programs at an affordable cost and with potential hardware and service demands that the library can meet.

These guidelines should continue to be useful even as the library moves toward loading databases into its online system. Questions pertinent to CDROM purchases will also apply to decisions about databases made available through public access terminals.

VCU is an urban university of more than 20,000 students. It includes a major medical school and extensive programs in business, education, the arts, and social work. The checklist that follows was, of course, developed in this context. But it can easily be modified to apply to academic communities of any kind.

\section{CD-ROM selection checklist}

Name of product:

Preferred vendor:

Brief description of product:

\section{Acquisition.}

1.1. What is the initial subscription cost of the product?

1.2. What, if any, are the costs for current disks and archival disks?
1.3. What are the ongoing costs, if any, for regular updates?

1.4. Is a discount applied to the cost if the product is already being purchased in a different format (print, microfiche, etc.)?

1.5. Is the product available through purchase (i.e., will the data be owned) or lease (i.e., will the data be rented)? For example, if the library cancels the product subscription, will the library keep or have to return the software and data disks?

1.6. Is this or similar information available from vendors other than the preferred vendor in electronic or other formats (compact disk, computer tape for a PAC)? What are the vendors, and what are their costs?

1.7. If the product is available from more than one vendor, why is the preferred vendor recommended?

1.8. Are there licensing requirements-i.e., site or hardware restrictions, limits on access to and use of data?

1.9. Can the product be networked?

1.10. If the product can be networked, what is the additional cost?

\section{Coverage.}

2.1. What subject area(s) does the product cover?

2.2. What is the scope of coverage?

2.3. How accurate is the data?

2.4. How thorough is the indexing?

2.5. Why is the intellectual level of the product appropriate for an academic library?

2.6. How will the product fill a curriculum support need?

2.7. Is the content suitable for ready reference, basic inquiry, or in-depth research?

2.8. Will the product assist us in responding to a demonstrated patron demand for information?

2.9. What other sources now available in the library cover this subject? How is the CD-ROM different?

2.10. What sources could it replace? What are the cost comparisons?

\subsection{How frequently is it updated?}

2.12. How does the content compare with the similar products mentioned in 1.6.?

\section{Software considerations.}

3.1. Describe the quality of the searching software. (Consider: multiple searchable fields; Boolean capability; online thesauri; online help screens; ability to interrupt the search process; variety of display, print, and download options; ability to replicate search strategies after changing disks; truncation; response time; ability to download data.)

3.2. Are the searching software's commands and protocols similar to those of the software we presently own?

3.3. Is there a commitment by the producer to 
make software compatible with all years/disks available, including archival disks?

3.4. Does the software meet High Sierra Group/NISO standards for the CD-ROM drive?

3.5. Why is the product easy for patrons and staff to use?

\section{Hardware considerations.}

4.1. Does the product run on hardware that we presently own?

4.2. If the product will not run on hardware that we presently own, what additional hardware is needed and what is its approximate cost?

4.3. Will the product's operating system be compatible with those systems already loaded on the same machine?

4.4. Based on current demand (online searches and/or referrals to print or microform sources) for the information available in this product, estimate the potential use of the product in terms of half-hour sessions per day or week.

4.5. Are the number of workstations presently available sufficient to support the projected use of the product? If not, what additional hardware will be necessary, and what is its approximate cost?

4.7. How many compact disks will be received with this product and how many additional disks will be added to the library's permanent collection each year?

4.8. Are present disk storage facilities adequate to store disk(s) acquired for this product? (This is particularly relevant to full-text databases.)

\section{Vendor support and documentation.}

5.1. What user documentation is available? Describe its quality.

5.2. Is there a toll-free hotline and/or other forms of user support?

\section{Service considerations.}

6.1. What staff is available to provide services for the product (training, loading software, troubleshooting, repair, etc.)?

6.2. What impact will the purchase have on online searching costs and staff time?

6.3. How will library policies rewarding CDROM usage (fees, restricted availability to certain patron tapes, etc.) affect patron access to the product?

This checklist has been used as a guide for several compact disk purchase proposals since its inception. Librarians have found the questions helpful in conversations with vendors, both in covering all aspects of a product and in leading the vendor into relating information not in the usual sales promotion. In some cases the questions were divided among a selection committee; thus several librarians could call one company. Often we got all the information we needed, and more. During several conversations with one company's salespeople, we received conflicting replies to question 1.5-were we to own or lease the product? At the time of this writing negotiations are still in progress.

In another instance, the reference department discussed and tested a product over a period of months and had come to believe that completing the checklist was merely a formality. However, new information came to light in response to question 3.3. We were surprised to learn that the software updates were not necessarily compatible with earlier disks. This caused a great deal of discussion, contrasting the strong desire to own the information in compact disk format with the practical problems of using different versions of software for different years of information. After these experiences, we face our future in CD-ROM with enthusiasm tempered by realism.

The process of using this checklist reinforced our initial feeling that it is an essential tool. It has proven to be highly useful in sorting out both the complex issues involved in CD-ROM selection and the variety of claims made by vendors. We would now be reluctant to make a CD-ROM product purchase without it.

\section{Book arts exhibit to tour Africa}

The United States Information Agency's Arts America Program is sending "Book Arts USA," an exhibition of the art and craft of the book, on a two-year tour of Africa, for presentation under U.S. Embassy auspices in Madagascar, Mauritius, Botswana, Malawi, Zimbabwe, Senegal, Côte d'Ivoire, and Mali. The USIA provided partial funding for the tour and served as coordinator with the Center for Book Arts, a publicly and privately funded gallery and educational center in New York, which organized the show.

Artist Richard Minsky served as curator for the exhibit, which features a 28-minute video wherein Minsky shows and discusses all of the books in the exhibit. Fifty-one North American artists are represented in the exhibit, reflecting the diversity and innovation of the contemporary American book. The books have been created from a wide range of materials, including handmade paper, Chiri Japanese paper, a walnut shell, Nigerian goatskin, rabbit fur, acrylic, vinyl, wood, gold foil, cast bronze and iron, feathers, buttons, and velvet. Some were handlettered; others were created on computers, printed on letterpress, watercolored, silkscreened, and lithographed. 